\title{
Discounting the Past: The Undervaluing of Paleontological Data in Conservation Science
}

\author{
Gregory P. Diett ${ }^{1,2 *}$, Jansen A. Smith ${ }^{1}$ and Stephen R. Durham ${ }^{1}$ \\ ${ }^{1}$ Paleontological Research Institution, Ithaca, NY, United States, ${ }^{2}$ Department of Earth and Atmospheric Sciences, Cornell \\ University, Ithaca, NY, United States
}

Keywords: climate change, conservation paleobiology, construal level theory, psychological distance, temporal discounting bias, disciplinary barriers

\section{INTRODUCTION}

OPEN ACCESS

Edited by:

G. Lynn Wingard, United States Geological Survey,

United States

Reviewed by:

Encarni Montoya, Instituto de Ciencias de la Tierra Jaume Almera (ICTJA), Spain Mark Bush,

Florida Institute of Technology, United States

*Correspondence:

Gregory P. Diet/ gpd3@cornell.edu

Specialty section:

This article was submitted to

Paleoecology,

a section of the journal

Frontiers in Ecology and Evolution

Received: 08 February 2019

Accepted: 19 March 2019

Published: 09 April 2019

Citation:

Dietl GP, Smith JA and Durham SR

(2019) Discounting the Past: The Undervaluing of Paleontological Data

in Conservation Science.

Front. Ecol. Evol. 7:108.

doi: 10.3389/fevo.2019.00108
Most paleontologists would probably agree that the field of conservation paleobiology (Dietl and Flessa, 2017) holds great promise in providing a long-term perspective on biotic responses to the major environmental stressors-pollution, invasive species, over-exploitation of wild species, habitat change, and climate change-threatening biodiversity today. Despite this potential, results from a recent survey aimed at characterizing the conception of "long-term" among marine conservation biologists-from a variety of workplaces and experience levels-indicated that not everyone shares the paleontological community's sentiment (Smith et al., 2018). When asked to select which timescales of data are needed to best address each stressor, marine conservation biologists tended to think that data on timescales of centuries and longer (i.e., paleontological data) were needed to address conservation issues related to climate change, but not the other four environmental stressors (Figure 1A).

This result was surprising given that all five stressors have deep roots in human history that date back more than a century. Arguably, the onset of anthropogenic climate change is the most recent of the five-the modern climate warming trend began around the turn of the last century, whereas multiple examples of industrial pollution, introduction of invasive species, fisheries collapse, and deforestation predate climate change by decades, centuries, or even millennia (MEA, 2005). We believe that this apparent lack of awareness of the utility of the past imperils wise environmental stewardship, which we urgently need in an "Anthropocene" world of rapid change.

Smith et al. (2018) interpreted the offset pattern of timescales as an indication that climate change was one of the most promising focal areas for integration of paleontological data and methods into conservation science, practice, and policy. However, they stopped short of explaining why the observed pattern for climate change might have been different from the other four stressors. One possibility is that the difference is related to the relative psychological distances of the five stressors. This difference may be influenced by the more intuitive need for long-term data to assess large-scale phenomena such as climate change, which-in contrast to the other four stressors-is explicitly defined as a large-scale phenomenon, as opposed to weather, its small-scale counterpart. Here, motivated by the (possibly naïve) belief that if more people had a feeling for the past the personal relevance and use of paleodata in conservation would increase, we develop this explanation for the climate change pattern based on the construal level theory (CLT) of psychological distance (Liberman and Trope, 2008, 2014; Trope and Liberman, 2010). 

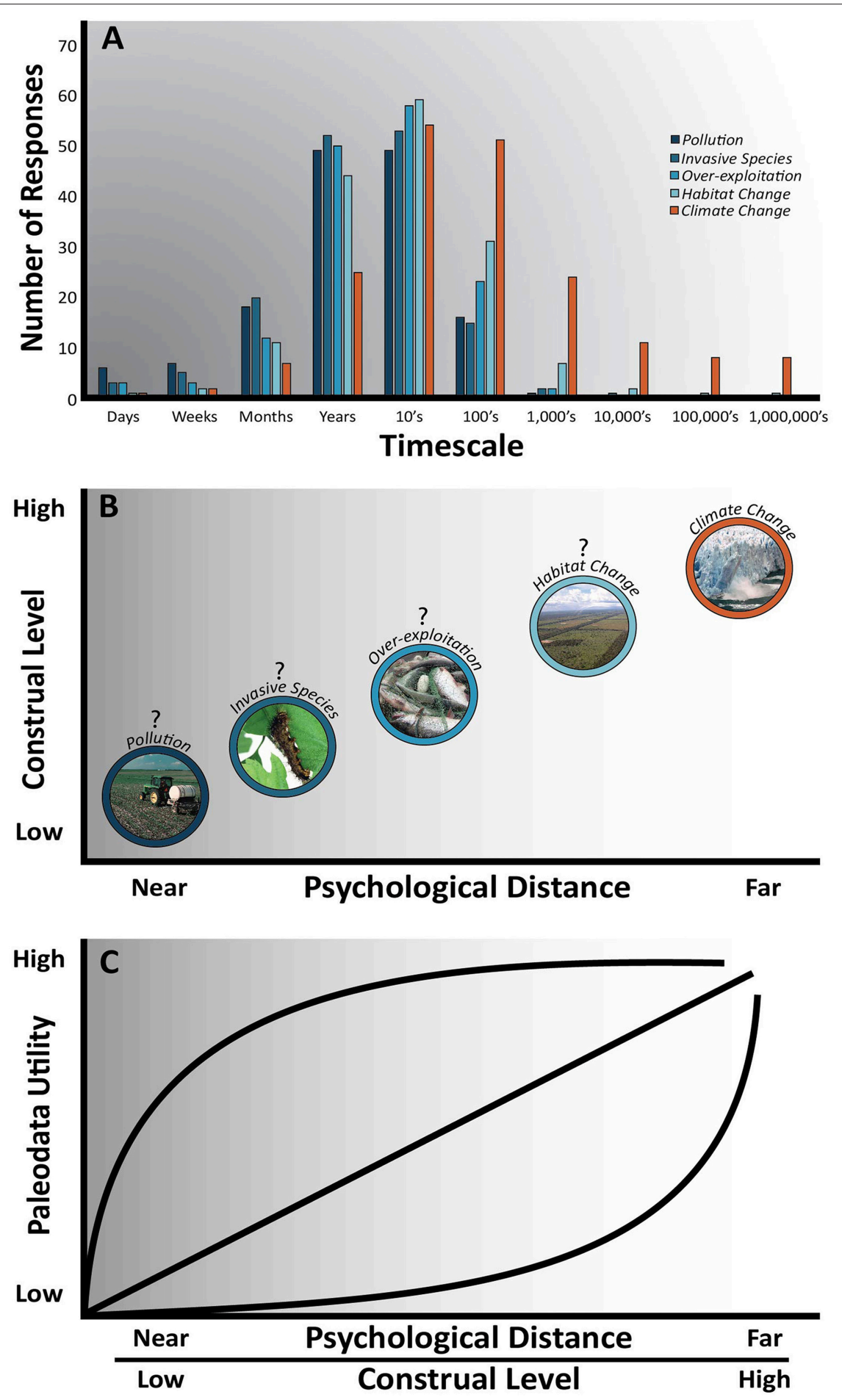

FIGURE 1 | (A) Distribution of timescales necessary to address the five major environmental stressors threatening biodiversity (adapted from Smith et al. (2018) with permission from Springer Nature). For pollution, invasive species, over-exploitation, and habitat change, the response median is between years and decades. For climate change responses, the median is between decades and centuries, with the distribution skewed toward longer timescales (Smith et al., 2018). (B) Hypothetical relationship between construal level and psychological distance for the five major environmental stressors threatening biodiversity today. To our knowledge, no empirical tests of the psychological distance and construal level of the pollution, invasive species, over-exploitation, and habitat change stressors have been conducted. We are most certain in the positioning of climate change at a high construal level and psychologically far distance; the question marks above the other four environmental stressors indicate our uncertainty in their placement. Relative order is based on estimates of the median timescale necessary to address each environmental stressor from the distributions in (A). (C) Hypothetical relationships between perceived paleodata utility and construal level/psychological distance. Multiple lines indicate our uncertainty in the relationship. 


\section{THE PSYCHOLOGY OF TRANSCENDING THE HERE AND NOW}

According to Liberman and Trope (2014), CLT posits that an object or event that is psychologically distant will be construed mentally in a "higher," more abstract way, than an object or event that is closer. The underlying assumption of CLT is that people can only directly experience the present situation. Moving beyond the realm of direct experience involves mental travel, that is, traversing psychological distance. Psychological distance can be conceptualized along four distinct (but interrelated) dimensions: social (e.g., family vs. strangers), time (e.g., near vs. distant past or future); physical space (e.g., close or far), and hypotheticality (e.g., certain vs. uncertain situations).

Events or objects are thought to be psychologically close when they focus on the immediate reality of the self. As events or objects drift away from this egocentric reference point, they become psychologically distant. What matters most is how far away the distance feels subjectively. People tend to associate each type of distance-social, temporal, spatial, and hypotheticalitywith the others, such that an event or object that is far in one dimension will be far in the others (Maglio et al., 2013).

Climate change risk is a widely discussed example of the phenomenon. For many people-particularly those living in western industrialized nations-climate change is perceived as distant along all four of the distance dimensions (Schuldt et al., 2018). For instance, along the spatial dimension, Leiserowitz (2006) showed that among adults in the United States the most frequent thought or image they associated with the term "global warming" was melting glaciers and polar ice, a spatially distant environmental impact for the majority of people living in the United States.

\section{DISCOUNTING THE PAST}

Why does CLT matter for conservation paleobiology? Recall that marine conservation biologists in the Smith et al. (2018) survey tended to think that longer term (=paleo) data were needed to address climate change but not the other four stressorspollution, invasive species, over-exploitation, and habitat change (Figure 1A). Based on CLT, we propose that the psychological distance of each environmental stressor might have influenced the perception of the utility of paleodata. Among the survey respondents, it is possible that they perceived climate change as a longer-term environmental stressor (i.e., a distant threat) but viewed the other stressors as psychologically closer (i.e., happening in the here and now) (Figure 1B). Assuming that paleodata are also perceived to be psychologically distant ${ }^{1}$ (i.e., less familiar) by most people-an assumption that seems likely given most people's struggles with thinking about geological time (Bjornerud, 2018) - the perceived utility of paleodata should be greatest when matched with other events or objects

${ }^{1}$ Rull $(2010$, 2014) speculated that this temporal bias may be related to the inherently human "psychological disconnection" between the "fragmentary" nature of evidence observable from the geological past compared to a more "continuous" present. that are also psychologically distant, with higher level, more abstract construals (Figure 1C). Thus, because climate change is a long-term process-perceived as an environmental stressor that is psychologically distant and involving higher level, more abstract construals - paleodata are more likely to be perceived as useful. In contrast, pollution, invasive species, over-exploitation, and habitat change might be perceived as environmental stressors that are psychologically closer and involving lower level, more concrete construals, such that paleodata are less likely to be perceived as useful.

We call this the "Discounting the Past" hypothesis. By "discounting" we mean the undervaluing of temporally distant paleodata as a consequence of a subconscious response to the psychological distance of the processes driving a given conservation problem. Such a perception, assuming support from empirical testing, complicates ongoing efforts to "mainstream" conservation paleobiology into real-world conservation because it reduces the personal relevance (i.e., buy-in) of paleodata, which itself is problematic because an individual's perception of the utility of paleodata is likely an important motivation to using such data in conservation practice in the first place. That is, psychological distance-in the form of temporal biasmight present an additional barrier that should be considered in tandem with more commonly acknowledged barriers to meaningful integration of paleodata in the future of conservation [e.g., methodological (Rull, 2010, 2014) and institutional (Smith et al., 2018) barriers] because the data most likely to be used in conservation practice are the data that are perceived as most closely matching the construal level of the problem at hand.

An important corollary of this idea is that the construals of different types of data may be an important factor in this "construal matching" as well. Although this idea extends somewhat beyond the scope of our essay, this data construal issue may be illustrated by the varying perceptions of paleodata within the field of paleontology. Even paleontologists-who, in light of Bjornerud's apt description of a "timefulness" worldview, are primed with a geologic habit of mind-are not immune to this temporal discounting bias. Anecdotally, we have heard some paleontologists profess that data from the distant past (i.e., tens and hundreds of millions of years ago) are not likely to be useful for solving conservation problems. The typical argument that is made by the skeptical paleontologist is that the organisms and environmental conditions of the distant past are so far removed from the immediate concerns of conservation biologists that the insights we might gain would be much too general to be useful or, better yet, actionable. Others in the field, however, consider the distant past to be "equally valuable" to the more familiar parts of the fossil record in which the organisms and habitats are most like today's but simply "less systematically pursued" for solving today's conservation problems (Dietl and Flessa, 2017).

Given what we have learned from CLT about how people mentally transcend the phenomenology of the here and now, we wonder whether paleodata from the distant past are construed at a higher (more abstract) level even by paleontologists, and what effect this subconscious process might have on their personal views of the utility of different types of paleodata for solving conservation problems. A similar bias could be 
influencing perceptions of other potentially useful types of data in conservation science as well.

\section{A WAY FORWARD}

We do not, at this time, have the necessary disciplinary knowledge to go beyond what we have speculated on here. Moving forward, new collaborations between environmental psychologists and conservation paleobiologists will need to be forged to test the discounting the past hypothesis and its corollary implications for perceptions of data. If the ideas we have presented here are correct, however, then increasing conservation biologists' feeling for the past might be a crucial step toward ultimately increasing the personal relevance (and use) of paleodata in conservation decision-making. In short, we must

\section{REFERENCES}

Bjornerud, M. (2018). Timefulness: How Thinking Like a Geologist Can Help Save the World. Princeton, NJ: Princeton University Press. doi: 10.2307/j.ctvc772cs

Dietl, G. P., and Flessa, K. W. (2017). Conservation Paleobiology: Science and Practice. Chicago: University of Chicago Press. doi: 10.7208/chicago/9780226506869.001.0001

Leiserowitz, A. (2006). Climate change risk perception and policy preferences: the role of affect, imagery, and values. Clim. Change 77, 45-72. doi: 10.1007/s10584-006-9059-9

Liberman, N., and Trope, Y. (2008). The psychology of transcending the here and now. Science 322, 1201-1205. doi: 10.1126/science.1161958

Liberman, N., and Trope, Y. (2014). Traversing psychological distance. Trends Cogn. Sci. 18, 364-369. doi: 10.1016/j.tics.2014.03.001

Maglio, S. J., Trope, Y., and Liberman, N. (2013). The common currency of psychological distance. Curr. Direct. Psychol. Sci. 22, 278-282. doi: $10.1177 / 0963721413480172$

MEA (2005). Ecosystems and Human Well-Being: Synthesis. Washington, DC: Island Press.

Rull, V. (2010). Ecology and palaeoecology: two approaches, one objective. Open Ecol. J. 3, 1-5. doi: 10.2174/1874213001003020001

Rull, V. (2014). Time continuum and true long-term ecology: from theory to practice. Front. Ecol. Evol. 2:75. doi: 10.3389/fevo.2014.00075 expand our mental horizon by finding novel ways to reframe our personal and collective thinking about the relevance of paleodata in conservation science, practice, and policy.

\section{AUTHOR CONTRIBUTIONS}

All authors were involved in developing the ideas presented in this paper. GD drafted the manuscript. JS and SD contributed to the writing and editing of the manuscript.

\section{ACKNOWLEDGMENTS}

We thank Encarni Montoya and Mark Bush for their thoughtful comments on the original version of this essay. We also thank Beth Stricker for her assistance with designing Figure 1.

Schuldt, J. P., Rickard, L. N., and Yang, Z. J. (2018). Does reduced psychological distance increase climate engagement? On the limits of localizing climate change. J. Environ. Psychol. 55, 147-153. doi: 10.1016/j.jenvp.2018. 02.001

Smith, J. A., Durham, S. R., and Dietl, G. P. (2018). "Conceptions of long-term data among marine conservation biologists and what conservation paleobiologists need to know," in Marine Conservation Paleobiology, eds. C. L. Tyler and C. L. Schneider (Cham: Springer Nature), 23-54.

Trope, Y., and Liberman, N. (2010). Construal-level theory of psychological distance. Psychol. Rev. 117, 440-463. doi: 10.1037/a0 018963

Conflict of Interest Statement: The authors declare that the research was conducted in the absence of any commercial or financial relationships that could be construed as a potential conflict of interest.

Copyright (C) 2019 Dietl, Smith and Durham. This is an open-access article distributed under the terms of the Creative Commons Attribution License (CC BY). The use, distribution or reproduction in other forums is permitted, provided the original author(s) and the copyright owner(s) are credited and that the original publication in this journal is cited, in accordance with accepted academic practice. No use, distribution or reproduction is permitted which does not comply with these terms. 